\title{
An investigation into the forming limits of sintered porous materials under different operational conditions
}

\author{
Cheng-Chao Huang, Jung-Ho Cheng* \\ Department of Mechanical Engineering, National Taiwan University, No. 1, Roosevelt Rd., Sec. 4, Taipei 10617, Taiwan, ROC
}

Received 23 October 2001; received in revised form 23 February 2002; accepted 31 October 2003

\begin{abstract}
This study is to investigate the forgeability of sintered porous materials under various operational conditions, including the aspect ratio (the height-to-diameter ratio) of billets, the void volume fraction, and the frictional conditions during the deformation. Experiments and finite element analysis were conducted to examine the process. The material properties of sintered preforms were ascertained from both the uni-axial tension and compression test. The finite element models were verified with the upsetting experiments under different frictional conditions. A new forming limit criterion for porous metals was formulated. Studies show that the aspect ratio bears a directly proportional relation to the fracture strain. The increase of voids deteriorates the strength and reduces the forging limits. Higher friction makes it easier to incur cracks in the workpiece and hence inhibits the workability.
\end{abstract}

(C) 2003 Published by Elsevier B.V.

Keywords: Porous materials; Powder forging; Plasticity; Finite element method; Forming limits; Workability

\section{Introduction}

Powder forging $(\mathrm{P} / \mathrm{F})$ combines powder metallurgy $(\mathrm{P} / \mathrm{M})$ and forging technology and thus possesses the advantages of both processes that result in both stronger and yet more versatile products with complicated geometry and arbitrary alloy compositions. Preforms are prepared in various steps that involve powder mixing, compacting, and sintering. The exact shape is obtained from a final forging procedure. However, voids in sintered compacts exert a damaging effect on the mechanical properties, and fracture may occur in workpieces as a result of major deformation in the forging process.

The workability of metals is one of the most important parameters that must be considered in the design of a forming operation. Ductile fracture criteria for a fully dense matrix were widely studied by Keeler and Backofen [1], Kobayashi [2,3], Lee and Kuhn [4,5], Roy et al. [6], Ettouney and Hardt [7], Darvas [8], McClintock [9], Sowerby and Chandrasekaran [10], Rice and Tracey [11], and Vujovic and Shabaik [12] based on the critical value of strain, the void volume fraction, or the hydrostatic component and the effective stress.

\footnotetext{
* Corresponding author. Fax: +886-2-2363-1755.

E-mail addresses: r1852206@w3.me.ntu.edu.tw (C.-C. Huang), jhcheng@w3.me.ntu.edu.tw (J.-H. Cheng).
}

The forming limit of porous preforms was a matter of great concern. Downey and Kuhn [13] applied the forgeability equation stemming from the strain ratio (the tensile strain/the compressive strain). Tabata and Masaki [14] proposed a fracture criterion with a formulation of the strain energy density. Then, a workability factor, which describes the effects of the mean stress and the effective stress [12], was utilized by Abdel-Rahman and El-Sheikh [15] in the upsetting test. Various existing localization conditions and fracture criteria were assessed by Lee and Zhang [16] in the finite element model to study the plastic flow and damage behavior of porous cylinders. The workability of porous metals under different forging conditions was also analyzed by Hartley et al. [17], Jha and Kumar [18], and Zhang et al. [19].

Despite the close scrutiny of the workability for a fully dense matrix or porous metals, the effects of forging conditions on the forming limits of sintered materials still elude sweeping generalization. The objective of this research, therefore, is to study the workability of sintered preforms under various forging conditions, including the aspect ratio (the height-to-diameter ratio), the void volume fraction, and the frictional effects (Fig. 1). This study started from preparing the porous specimens with metal powder via appropriate $\mathrm{P} / \mathrm{M}$ approaches. The material properties of the sintered compacts were ascertained from the simple tension and compression test. Then, the finite element models were established and verified with the upsetting experi- 


\begin{tabular}{|ll|}
\hline Nomenclature \\
$E$ & Young's modulus \\
$f$ & void volume fraction (porosity) \\
$\dot{f}$ & total change of void volume fraction \\
$f_{\mathrm{c}}$ & porosity at the crack point \\
$\dot{f}_{\mathrm{g}}$ & change of growth of existing voids \\
$\dot{f}_{\mathrm{n}}$ & change of nucleation of new voids \\
$\mathbf{I}$ & identity matrix \\
$k$ & coefficient in the plastic equation of a \\
& fully dense matrix \\
$m$ & material constant \\
$n$ & strain hardening exponent \\
$p$ & contact pressure \\
$q_{1,2,3}$ & material parameters \\
$\mathbf{S}$ & deviatoric part of the Cauchy stress tensor \\
& \\
$G r e e k$ & letters \\
$\varepsilon_{r \mathrm{c}}$ & intercept of the fracture line for a matrix \\
& on the tensile strain axis \\
$\varepsilon_{z \mathrm{c}}$ & critical compressive strain (axial strain) \\
$\varepsilon_{\theta \mathrm{c}}$ & critical tensile strain (circumferential strain) \\
$\bar{\varepsilon}_{\mathrm{m}}^{\mathrm{p}}$ & effective plastic strain of a fully dense \\
$\dot{\boldsymbol{\varepsilon}}^{\mathrm{p}}$ & matrix \\
$\dot{\bar{\varepsilon}}_{\mathrm{m}}^{\mathrm{p}}$ & plastic flow of the materials \\
$\dot{\lambda}$ & effective plastic flow of a fully dense \\
$\mu$ & matrix \\
$\nu$ & non-negative plastic flow multiplier \\
$\sigma$ & coefficient of friction \\
$\bar{\sigma}$ & Poisson's ratio \\
$\bar{\sigma}_{\sigma_{\text {first yield }}}$ & macroscopic Cauchy stress tensor \\
& first yield stress of porous materials or a \\
$\sigma_{\mathrm{h}}$ & fully dense matrix \\
$\sigma_{\mathrm{y}}$ & hydrostatic stress \\
$\tau_{\mathrm{crit}}$ & flow stress of a fully dense matrix \\
$\tau_{\mathrm{eq}}$ & critical stress \\
$\tau_{1,2}$ & equivalent frictional stress \\
$\mathbf{\Phi}$ & potential function \\
& \\
\hline
\end{tabular}

ments under different frictional conditions. At the last step, the forging limits of the sintered preforms under different operational conditions were thoroughly discussed.

\section{Theoretical background}

\subsection{Yield function for porous media}

The plastic theories of porous materials have been widely examined. Gurson [20] proposed a yield criterion for porous media based on a rigid-plastic upper bound solution for spherically symmetric deformations of a single spherical void in the unit cell. This criterion combines the effects of both the deviatoric part and the hydrostatic component, and is represented as follows:

$\boldsymbol{\Phi}(\sigma, f)=\left(\frac{\bar{\sigma}}{\sigma_{\mathrm{y}}}\right)^{2}+2 q_{1} f \cosh \left(\frac{3 q_{2} \sigma_{\mathrm{h}}}{2 \sigma_{\mathrm{y}}}\right)-\left(1+q_{3} f^{2}\right)=0$,

where

$\bar{\sigma}=\sqrt{\frac{3}{2} \mathbf{S}: \mathbf{S}}$

is the von Mises effective stress,

$\mathbf{S}=\boldsymbol{\sigma}-\sigma_{\mathrm{h}} \mathbf{I}$

is the deviatoric part of the macroscopic Cauchy stress tensor $\sigma$,

$\sigma_{\mathrm{h}}=\frac{1}{3} \sigma: \mathbf{I}$

is the hydrostatic stress, and I the identity matrix, meanwhile, $\sigma_{\mathrm{y}}$ the flow stress of a fully dense matrix, $f$ the void volume fraction, and $q_{1}, q_{2}$, and $q_{3}$ are the material parameters. Originally, it was shown that $q_{1}=q_{2}=q_{3}=1$ in Eq. (1). Then, the scalar parameters with $q_{1}=1.5, q_{2}=1$, and $q_{3}=q_{1}^{2}$ were introduced by Tvergaard [21]. With the value of porosity being given as zero, $f=0$, the GursonTvergaard criterion can be simplified to the von Mises formula for the fully dense matrix

$\boldsymbol{\Phi}(\boldsymbol{\sigma})=\bar{\sigma}-\sigma_{\mathrm{y}}=0$.

On the other hand, the plastic flow of the materials is assumed to be normal to the yield surface

$\dot{\boldsymbol{\varepsilon}}^{\mathrm{p}}=\dot{\lambda} \frac{\partial \boldsymbol{\Phi}}{\partial \boldsymbol{\sigma}}$,

where $\dot{\lambda}$ is the non-negative plastic flow multiplier.

The hardening of a fully dense matrix is described by the constitutive equation

$\bar{\sigma}=\bar{\sigma}\left(\bar{\varepsilon}_{\mathrm{m}}^{\mathrm{p}}\right)$,

where $\bar{\varepsilon}_{\mathrm{m}}^{\mathrm{p}}$ is the effective plastic strain of a matrix. The effective plastic flow of a matrix, $\dot{\bar{\varepsilon}}_{\mathrm{m}}^{\mathrm{p}}$, is obtained from the following effective plastic work expression:

$(1-f) \sigma_{\mathrm{y}} \dot{\bar{\varepsilon}}_{\mathrm{m}}^{\mathrm{p}}=\sigma: \dot{\boldsymbol{\varepsilon}}^{\mathrm{p}}$.

\subsection{Void evolution}

Voids in sintered powder compacts exert a detrimental effect on the mechanical properties and the forming limits. The total change of the void volume fraction in the porous metals during deformation arises partly from the growth of existing voids and partly from the nucleation of new voids, a fact that can be stated as

$\dot{f}=\dot{f}_{\mathrm{g}}+\dot{f}_{\mathrm{n}}$, 


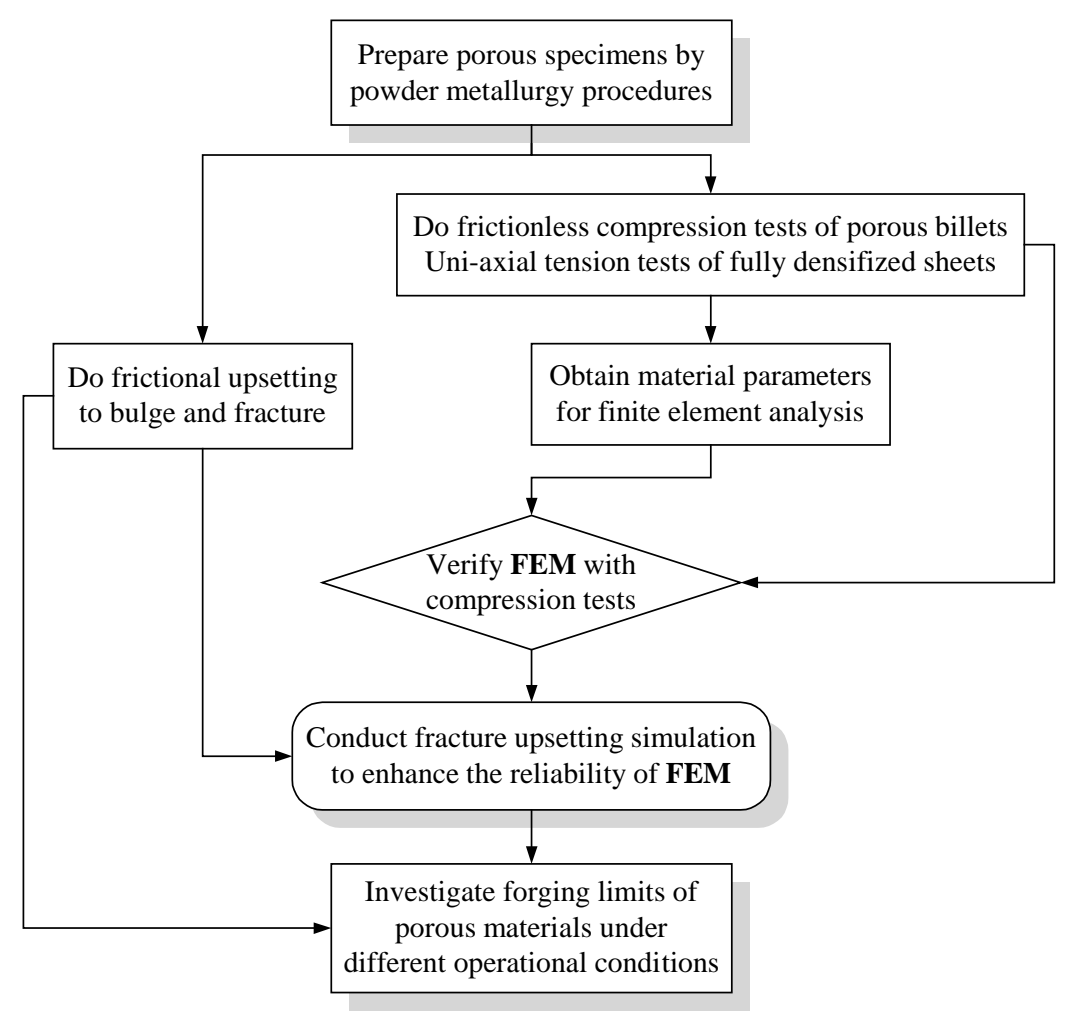

Fig. 1. The flow chart of this research.

where $\dot{f}_{\mathrm{g}}$ is the growth rate of existing voids and $\dot{f}_{\mathrm{n}}$ the change of the nucleation of new voids. The growth of existing voids is formulated based on the law of conservation of mass and is expressed as

$\dot{f}_{\mathrm{g}}=(1-f) \dot{\boldsymbol{\varepsilon}}^{\mathrm{p}}: \mathbf{I}$.

On the other hand, the nucleation of new voids stems from the grain boundaries or decohesion of the particle-matrix interface in the tensile stress state. Void nucleation at a material point, therefore, will not be considered in the compressive stress state. The mechanisms of void growth and nucleation during plastic deformation were subsequently reviewed by Goods and Brown [22], Chu and Needleman [23], Hom and McMeeking [24], and Lee and Zhang [25].

\subsection{Frictional conditions}

A standard Coulomb friction model, with an additional limit on the allowable shear stress, was used to describe the contact situations. It is assumed that no relative motion occurs if the equivalent frictional stress

$\tau_{\mathrm{eq}}=\sqrt{\tau_{1}^{2}+\tau_{2}^{2}}$

is less than the critical stress, $\tau_{\text {crit }}$, which is proportional to the contact pressure, $p$, in the form below

$\tau_{\text {crit }}=\mu p$, where $\mu$ is the coefficient of friction. In addition, $\tau_{1}$ and $\tau_{2}$ in Eq. (11) are the components of the shear stress.

\subsection{Material parameters}

The Gurson-Tvergaard yield criterion was adopted to describe the plastic behavior of porous metals, where the scalar parameters, $q_{1}, q_{2}$, and $q_{3}$, were determined empirically in this study. The processes of fitting these parameters were derived from our previous work [26]. Other material constants of the matrix were measured with the simple test as well.

\section{Experimental work}

\subsection{Specimens preparation}

The porous specimens used in the experiments were prepared from the water-atomized pure iron powder. Various compacting pressures and the floating die method were utilized to obtain cylindrical billets with different green densities and aspect ratios. All the compacts were sintered in dry hydrogen at $1200^{\circ} \mathrm{C}$ for $1 \mathrm{~h}$ and then cooled down in the furnace to room temperature. In order to determine the mechanical properties of the matrix, some specimens were fully densified by rolling. Then, the process of recrystallization was applied in dry hydrogen at $600^{\circ} \mathrm{C}$ to dispel the hardening induced in rolling. 


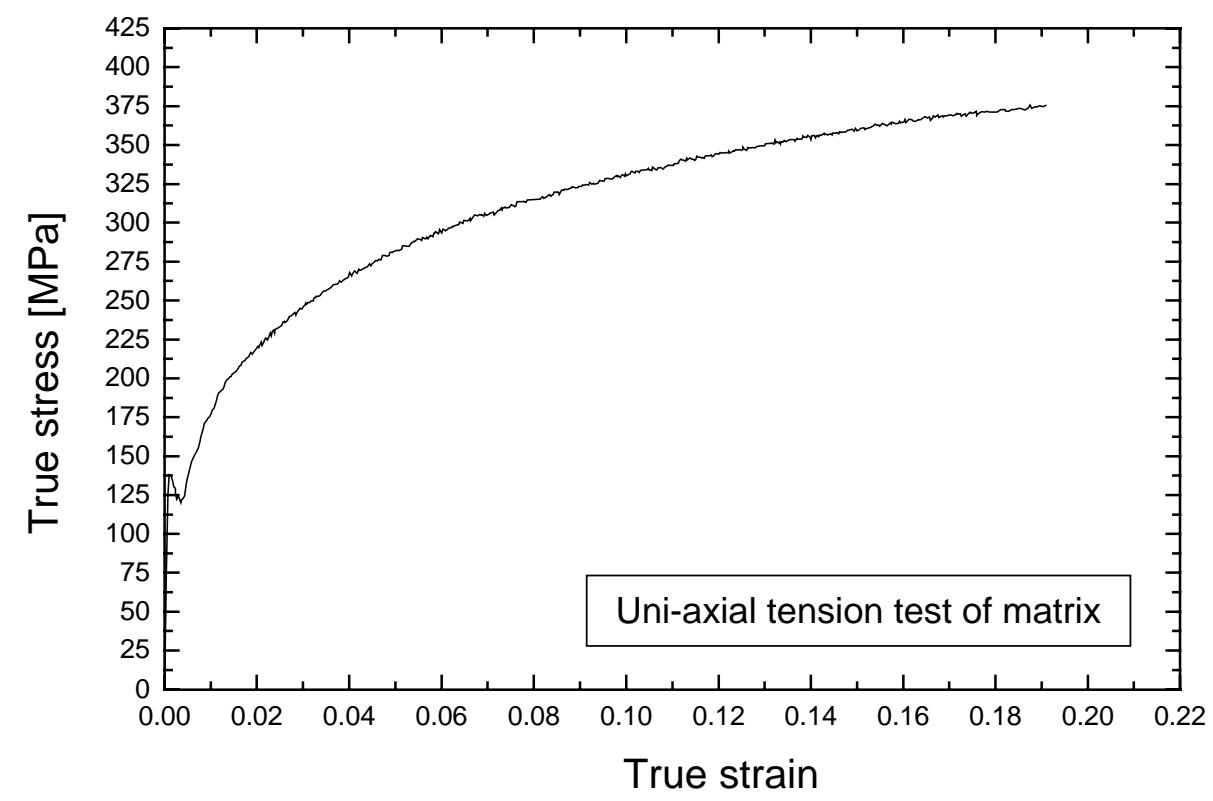

Fig. 2. The tensile true stress-strain curve of the fully dense matrix by experiment.

\subsection{Uni-axial tension tests}

The material properties, Young's modulus, Poisson's ratio, first yield stress, and the plastic behavior of the fully dense matrix were obtained from the uni-axial tension test. A strain gauge and an extensometer were utilized to monitor the deformation in the axial and transverse directions. The tensile true stress-strain curve of a fully dense matrix is shown in Fig. 2, where the first yield stress is found to be $126 \mathrm{MPa}$. The plastic behavior of the matrix reveals a power law relation

$\bar{\sigma}=k\left(\bar{\varepsilon}_{\mathrm{m}}^{\mathrm{p}}\right)^{n}$,

where the coefficient $k$ is fitted at the value of $543.63 \mathrm{MPa}$ and the strain hardening exponent $n$ is about 0.3 .

\subsection{Frictionless compression tests}

For the frictionless upsetting test, the porous billets with various initial relative densities were tested under the compressive loading and Teflon sheets were used as a lubricant to maintain the uniform deformation of these specimens. Because of the compressibility of porous billets, the current cross-section of the billets during the deformation could not be determined with the classical plasticity theory for the matrix. The diameter gauge, as shown in Fig. 3, was constructed to measure the current diameters of the porous billets in the frictionless upsetting, which is something imperatively needed to calculate the current area by the assumption of the circular cross-section. Therefore, the true stress in the material during the tests could be computed by dividing the current area into the axial load. On the other hand, the instantaneous heights of the billets were measured by the extensometer. Meanwhile, the void evolution was ascertained from the total change of the volume of the specimen, where the volume was calculated by multiplying the current area and the instantaneous height.

For each frictionless upsetting test, the first yielding point is identified via the intersection of the true stress-strain curve and the line that shifted $0.2 \%$ off the elastic region. The first yield stress-porosity data, obtained by upsetting the billets with various initial relative densities, are given in Fig. 4. A third-order polynomial function was used to fit these data, and the empirical curve was obtained as follows:

$\sigma_{\text {first yield }}=-126.31+482.66 f-692.70 f^{2}+389.14 f^{3}$,

where $\sigma_{\text {first yield }}$ is the first yield stress and $f$ the porosity at the first yielding state. The fitting curve meets the vertical axis at $-126.31 \mathrm{MPa}$, which resembles the first yield stress of the fully dense matrix in magnitude (Fig. 2). Then, these scalar parameters were determined by fitting Eq. (14) into Eq. (1), the procedures of which were presented in our previous study [26]. The values of Young's modulus, E, Poisson's ratio, $v$, the first yield stress of the matrix, $\sigma_{\text {first yield, and }}$ the scalar parameters of the porous metals are all shown in Table 1.

\subsection{Fracture upsetting tests}

Upsetting experiments without Teflon sheets were done to perform the frictional compression and to determine the fracture strokes of the billets with various initial relative densities and at differing aspect ratios; meanwhile, the load-displacement curves toward a fracture were obtained. 


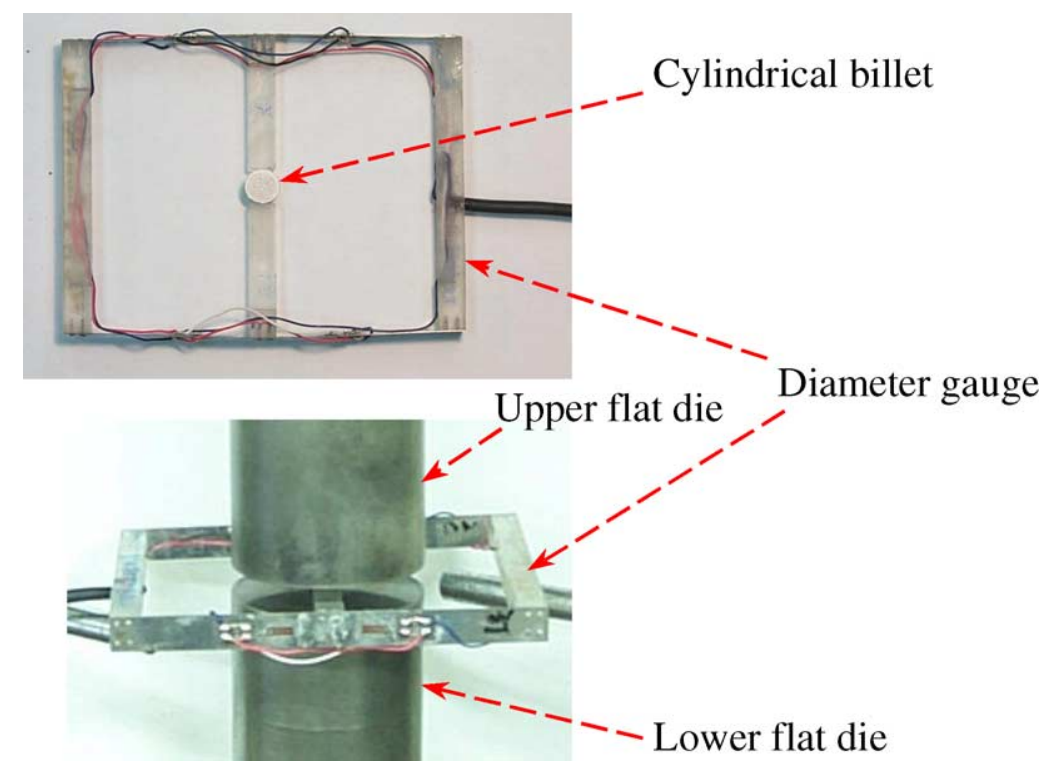

Fig. 3. The construction of the diameter gauge in the compression test.

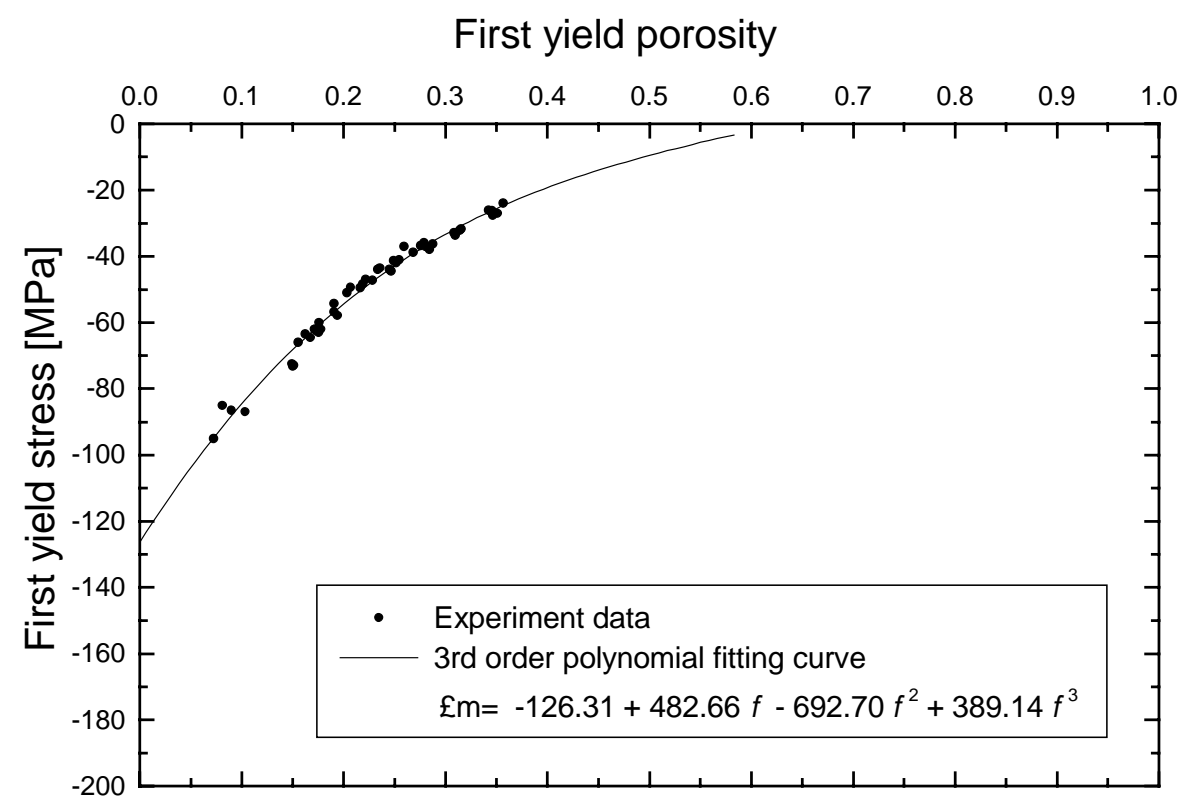

Fig. 4. Comparison of the first yield stress-porosity data by experiment and the non-linear curve by fitting.

Table 1

The material constants

\begin{tabular}{lc}
\hline Matrix property & \\
$E(\mathrm{GPa})$ & 180 \\
$v$ & 0.27 \\
$\sigma_{\text {first yield }}(\mathrm{MPa})$ & 126 \\
Porous parameter & \\
$q_{1}$ & 1.81 \\
$q_{2}$ & 1.00 \\
$q_{3}$ & 2.80 \\
\hline
\end{tabular}

The tension and compression tests were conducted using the MTS 810 material testing system, and the experiments were compared with the finite element analysis.

\section{Verification of finite element analysis}

\subsection{Model construction}

ABAQUS/Standard [27] was used to model and analyze the forging of porous compacts. The material properties and deformation characteristics are very complicated in real 


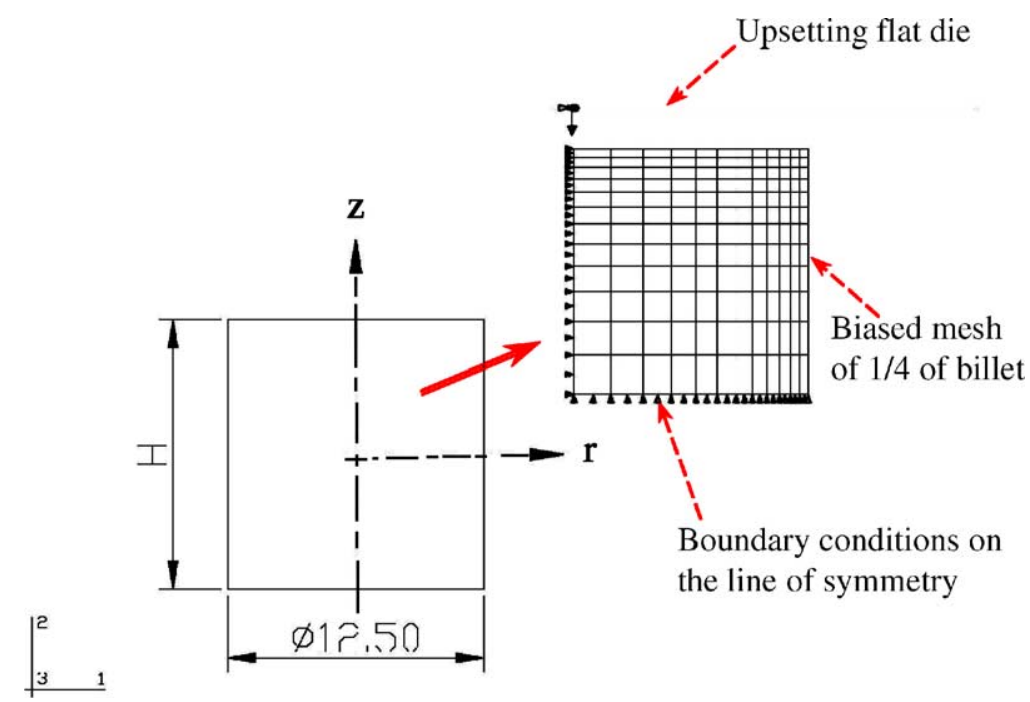

Fig. 5. The finite element mesh and the boundary conditions of the billet in the upsetting analysis.

cases; therefore, some reasonable assumptions were made to simplify the analysis:

1. The matrix is perfectly bonded and incompressible.

2. The void distribution is homogeneous in the specimen.

3. The cylindrical billets are uniformly deformed during the frictionless upsetting.

The finite element mesh and the boundary conditions of the cylindrical billet in the open flat die upsetting analysis are shown in Fig. 5. Because of the axisymmetric profile, only a quarter of each cylindrical billet and die were modeled. The discretization was biased toward the outward region to account for the larger amounts of deformation and the contact situations. The four-node bilinear axisymmetric solid element was used for the billet, and the rigid surface was used for the open flat die.

\subsection{Upsetting simulations under frictionless and frictional conditions}

In order to verify the finite element results with experiments, the upsetting simulation with two different frictional conditions was considered. The coefficient of friction was given as zero in the frictionless analysis, in which the uniform deformation of the billets was preserved. The results were used to examine whether the data experimentally determined truly represented the actual bulk material behavior. Then, the frictional upsetting analysis was carried out with

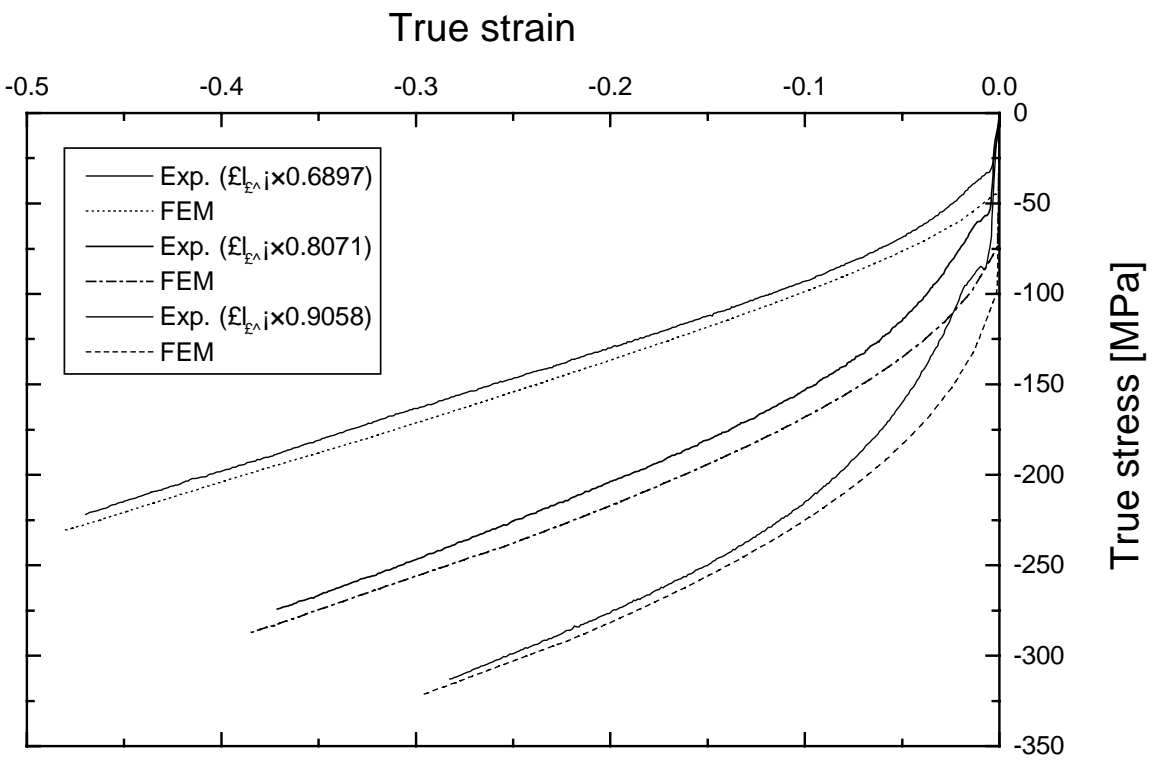

Fig. 6. Comparison of the true stress-strain curves in the frictionless upsetting by experiment and FEM 


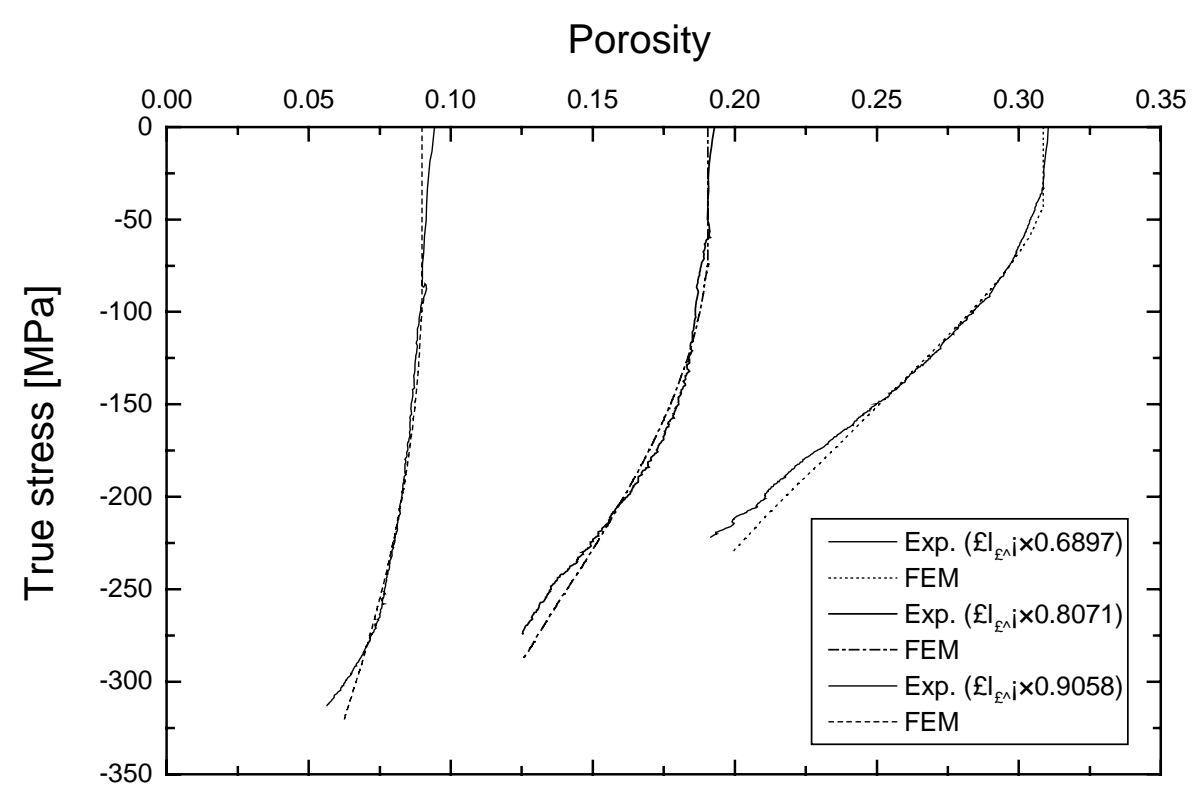

Fig. 7. Comparison of the true stress-porosity curves in the frictionless upsetting by experiment and FEM.

an equivalent coefficient of friction, 0.2 , which provided a similar bulged profile in loading history to the specimens from the experiments.

The compressive true stress-strain curves and the true stress-porosity curves with the initial relative densities of $0.6897,0.8071$, and 0.9058 under frictionless conditions are illustrated in Figs. 6 and 7. The results indicate that finite element simulations closely match the measured data with slight discrepancies. Fig. 6 depicts that the yield strength and loading capacity of the workpiece deteriorate with the presence of voids. In Fig. 7, the curves reveal the evolution of voids during the frictionless upsetting process. Void reduction is governed by the volumetric plastic strain, which is caused by the hydrostatic pressure.

As another example of validation, the same upsetting process with frictional conditions was computed. The loaddisplacement curves toward the crack initiation on the billets with the initial relative densities of $0.7022,0.8079$, and 0.9131 by experiment and simulation are compared in Fig. 8, while the data of the geometry, the fracture stroke, and the porosity at the crack point are exhibited in Table 2 . Voids decrease the workability of the workpiece. Friction

\section{Displacement [mm]}

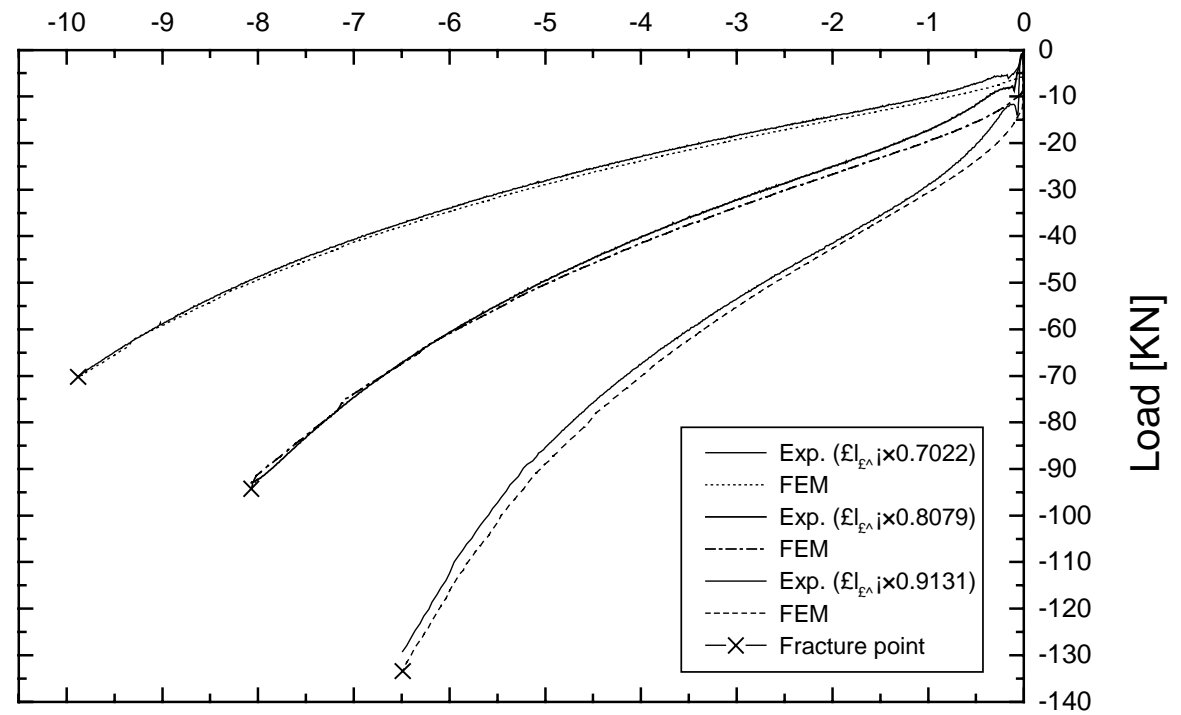

Fig. 8. Comparison of the load-displacement curves toward a fracture in the frictional upsetting by experiment and FEM. 
Table 2

The data of the porous billets in the fracture upsetting tests

\begin{tabular}{lllll}
\hline $\begin{array}{l}\text { Initial relative } \\
\text { density }\end{array}$ & $\begin{array}{l}\text { Height } \\
(\mathrm{mm})\end{array}$ & $\begin{array}{l}\text { Diameter } \\
(\mathrm{mm})\end{array}$ & $\begin{array}{l}\text { Fracture } \\
\text { stroke }(\mathrm{mm})\end{array}$ & $\begin{array}{l}\text { Porosity at the } \\
\text { crack point }\end{array}$ \\
\hline 0.7022 & 18.79 & 12.50 & -9.8756 & 0.2373 \\
0.8079 & 15.55 & 12.51 & -8.0729 & 0.1426 \\
0.9131 & 11.92 & 12.52 & -6.4902 & 0.0794 \\
\hline
\end{tabular}

at contact interfaces leads to non-uniform deformation and density variation, which cause the billets to bulge out and fracture at the equator of the bulge surface.

\section{Results and discussion}

Bulk forming effects complicated deformation, a process that reflects the workability of materials. It is very important to guide the production practice according to the forming limits. The verified finite element model was utilized to study the forging limits of sintered materials under different operational conditions, including the aspect ratio of billets, the void volume fraction, and the friction at contact interfaces. The results are discussed separately in the following sections.

\subsection{Effects of aspect ratios of billets}

Since fracture occurs as a result of the tensile strain, the fracture strain could be considered as a forming limit criterion in working operations. In this research, the forging limits in terms of the local fracture strain on the tensile strain axis over the compressive strain axis are adopted to describe the workability of porous metals.
The data on the fracture strain of billets, which have several kinds of aspect ratios, with the initial relative densities of about $0.70,0.81$, and 0.91 under frictional conditions in the upsetting analysis, are illustrated in Figs. 9-11, respectively. The aspect ratios of the billets in Fig. 11 are larger than those in Figs. 9 and 10. According to the results shown in Figs. 9-11, the increasing aspect ratio of the porous billets can proportionally enhance the tensile and compressive strain at a fracture. However, buckling arises from the excessive aspect ratio. The locus of the fracture strains in each figure fits a straight line, exerting a slope of one half. These straight lines by fitting are parallel to the strain path for homogeneous deformation (the dashed line) in the frictionless compression.

In the course of the homogeneous compression without friction, the free-spreading cylindrical surfaces remain straight (without bulge), and surface defects will not occur at the zero stress on the circumference. However, any strain path that moves upward from the line of homogeneous deformation will lead to a fracture once the tip of the path meets the fracture locus, a reaction is dependent on materials and operational conditions.

\subsection{Effects of void volume fraction}

In this study, we assumed that the change in the void volume fraction was brought about by the variation of existing voids and that the nucleation of new voids in the tensile stress was negligible.

The fracture loci of the billets with different initial relative densities in the upsetting test are shown in Fig. 12, where the data given are organized from the preceding three figures. According to these loci, the forming limit criterion for the porous billets is formulated with the following

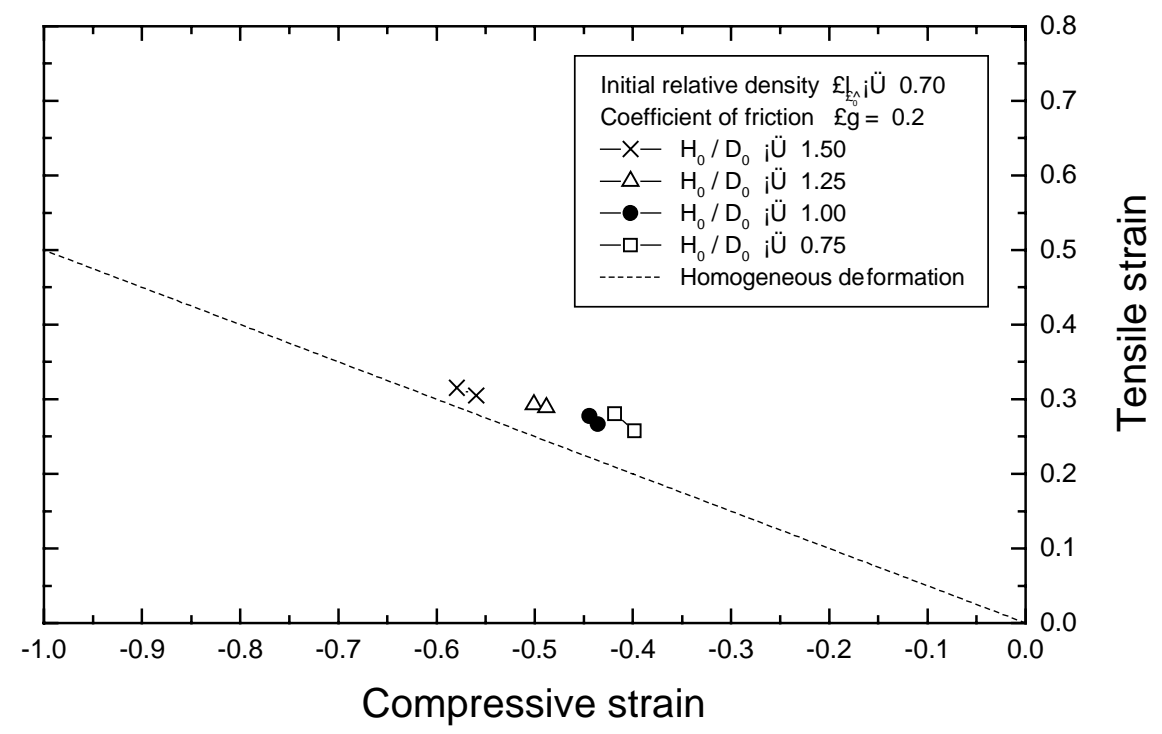

Fig. 9. The fracture strain of the billets with the initial relative density of about 0.70 , at differing aspect ratios, in the analysis of the actually frictional upsetting. 


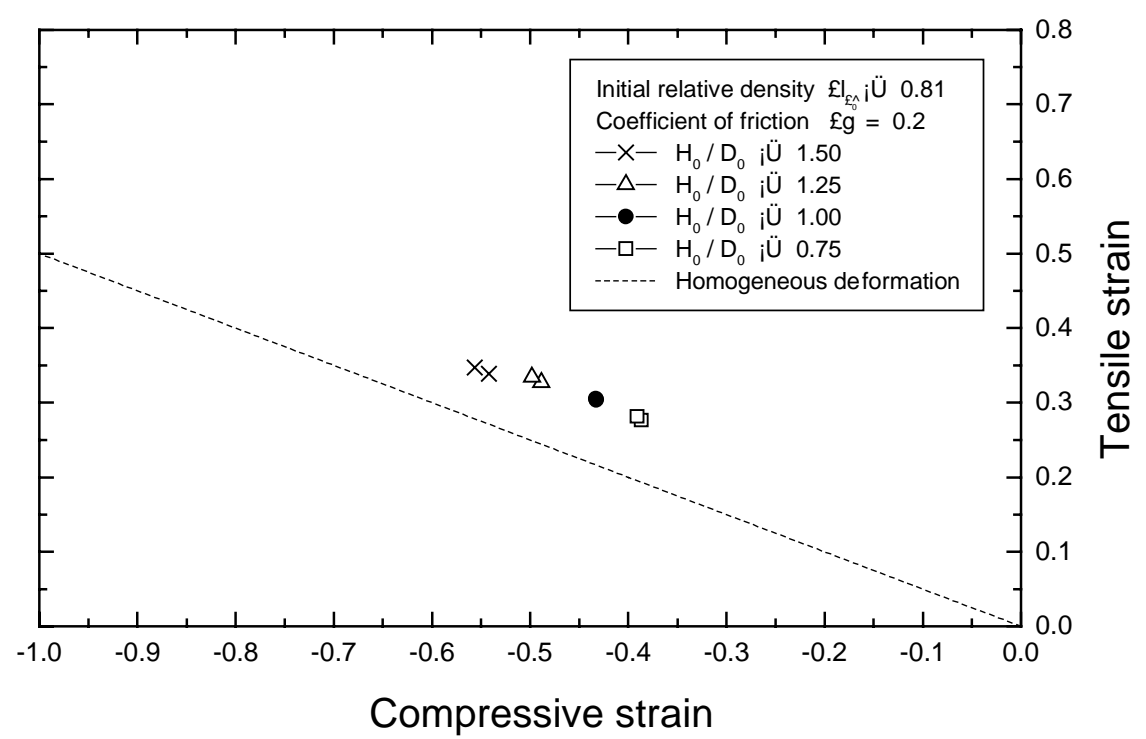

Fig. 10. The fracture strain of the billets with the initial relative density of about 0.81 , at differing aspect ratios, in the analysis of the actually frictional upsetting.

equation:

$\varepsilon_{\theta \mathrm{c}}=-\frac{1}{2} \varepsilon_{z \mathrm{c}}+\varepsilon_{r \mathrm{c}} \mathrm{e}^{-m f_{\mathrm{c}}}$

where $\varepsilon_{\theta \mathrm{c}}$ is the critical tensile strain in the circumferential direction, $\varepsilon_{z \mathrm{c}}$ the critical compressive strain in the axial direction, and $f_{\mathrm{c}}$ the porosity at the crack point. With the data shown in Fig. 12 and Table 2, the intercept of the fracture locus for the matrix on the tensile strain axis, $\varepsilon_{r \mathrm{c}}$, is fitted at the value of 0.2282 , while the material constant, $m$, is determined with the value of 7.1311 .

The existence of voids exhibits an exponential-decaying relation to the forming limits of sintered materials, indicating that the fracture loci shift downward as the cavity increases. As the porosity at the crack point is reduced to be zero, the fracture line of the fully dense matrix is generated, as shown in Fig. 12. This criterion, verified with the upsetting experiments, could be applied to evaluate a fracture in more complex practices.

\subsection{Effects of frictional conditions}

The friction at contact interfaces of preforms and dies plays an important role in the deformation characteristics and the forging limits of sintered materials. The average co-

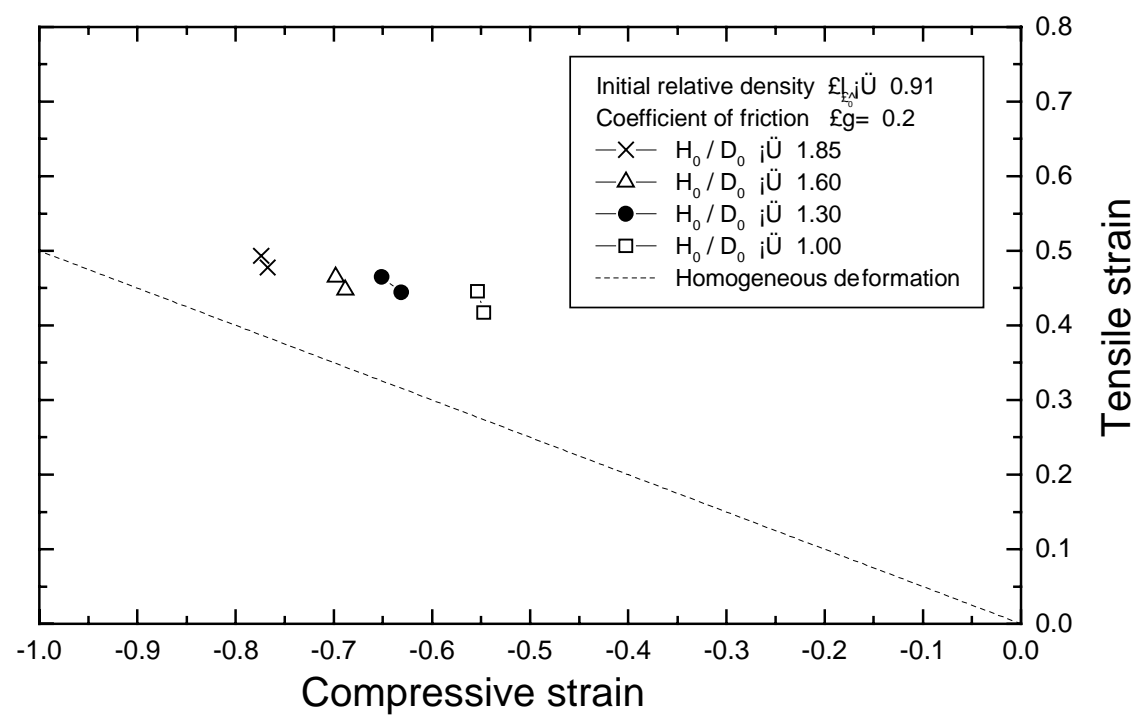

Fig. 11. The fracture strain of the billets with the initial relative density of about 0.91 , at differing aspect ratios, in the analysis of the actually frictional upsetting. 


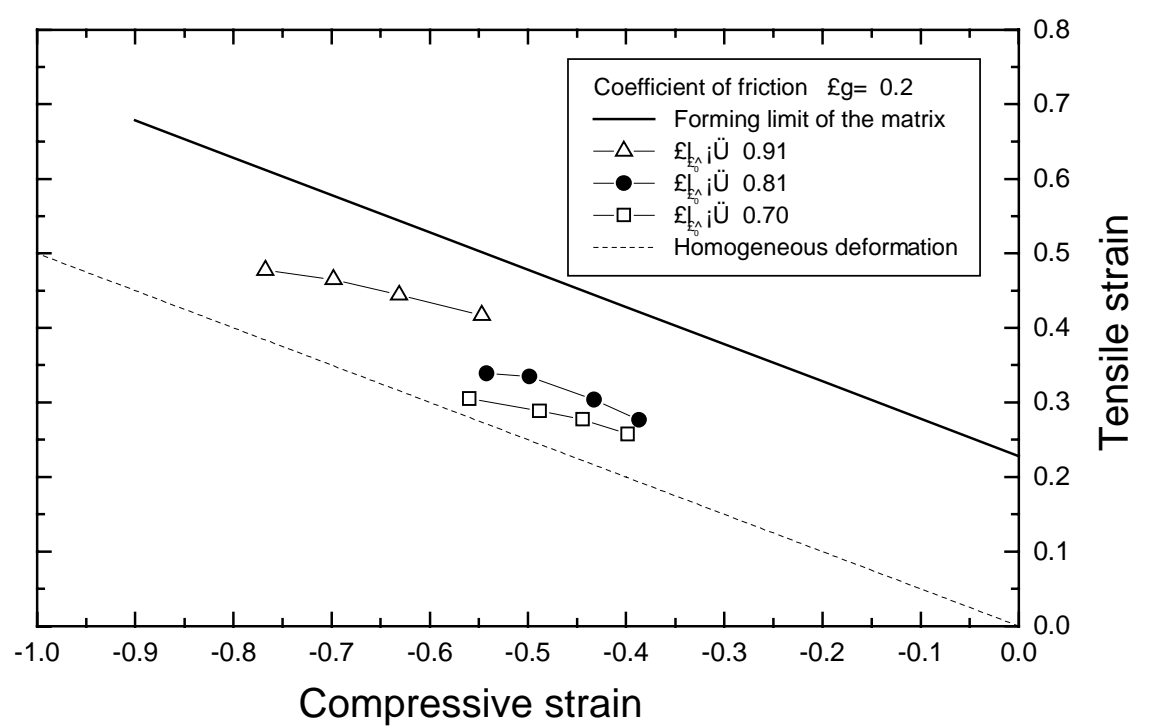

Fig. 12. The fracture strain loci of the billets with different initial relative densities and the forming limit of the matrix in the analysis of the actually frictional upsetting.

efficients of friction in the upsetting experiments were determined from comparing the test results with the finite element solutions. In order to study the effects of frictional conditions on the workability of sintered materials, the simulation of the fracture upsetting under various contact situations was made as well.

The results of the fracture loci with the initial relative densities of about $0.70,0.81$, and 0.91 under different coefficients of friction are illustrated in Figs. 13-15, respectively. From these three figures, the different frictional conditions have significant influence on the fracture loci of porous billets. The increasing friction only in- hibits the compressive strain, resulting in lower forging limits, while the tensile strain at a fracture remains constant.

Under the contact situations of high friction, the curvature of the bulge profile on the free surface is more obvious, containing the variation of the void volume fraction. Meanwhile, the damage forms and coalesces in the barreling area, where the tensile stress exists. Therefore, a higher friction degrades the forming limits, indicating that the defects occur early. In order to improve the quality of the products, the lubrication conditions should be improved to forestall fracture initiation in the working process.

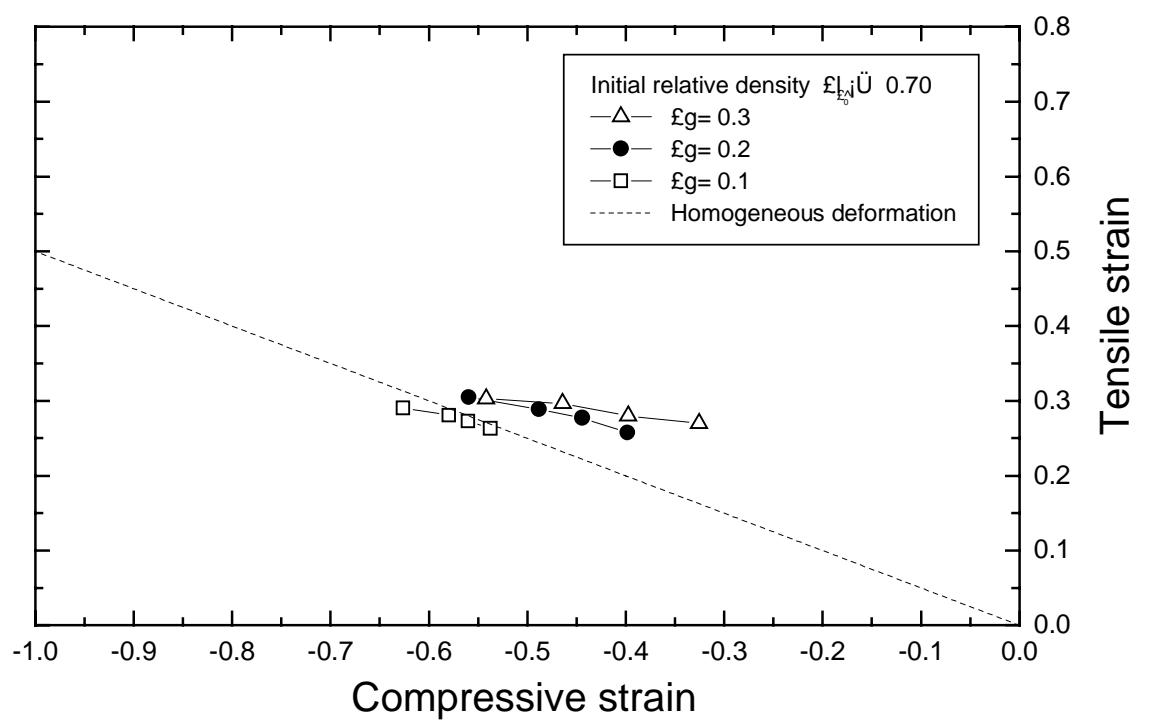

Fig. 13. The fracture strain loci of the billets with the initial relative density of about 0.70 under different coefficients of friction in the upsetting analysis. 


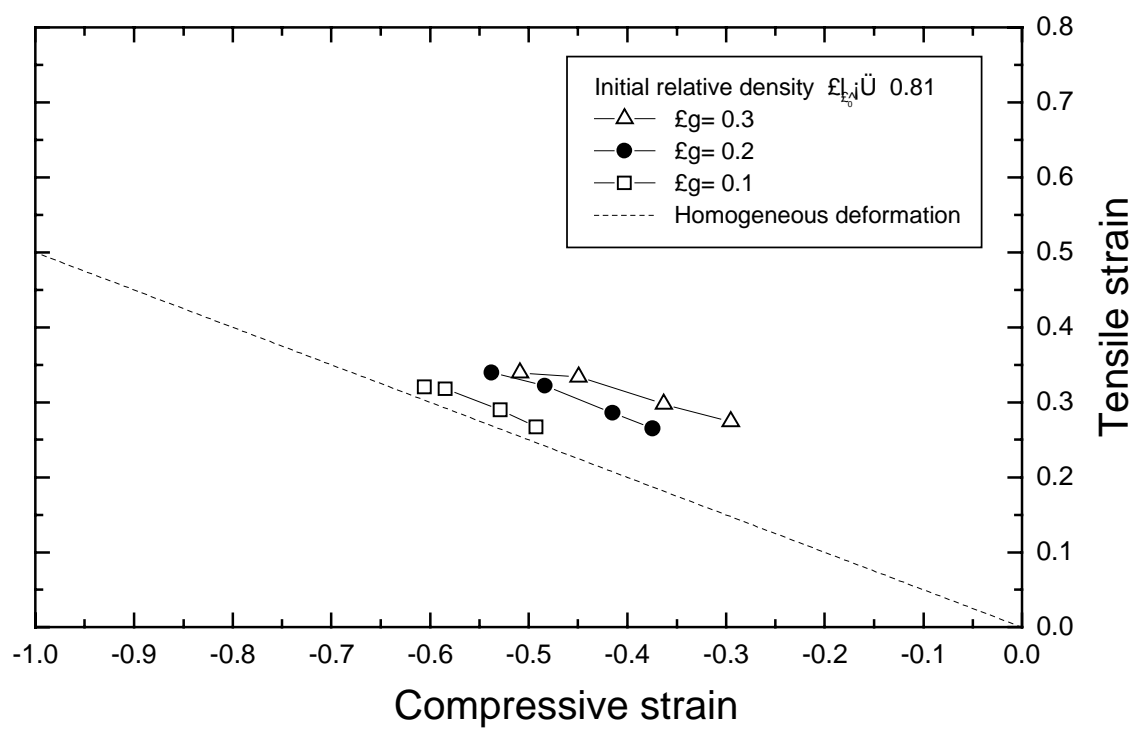

Fig. 14. The fracture strain loci of the billets with the initial relative density of about 0.81 under different coefficients of friction in the upsetting analysis.

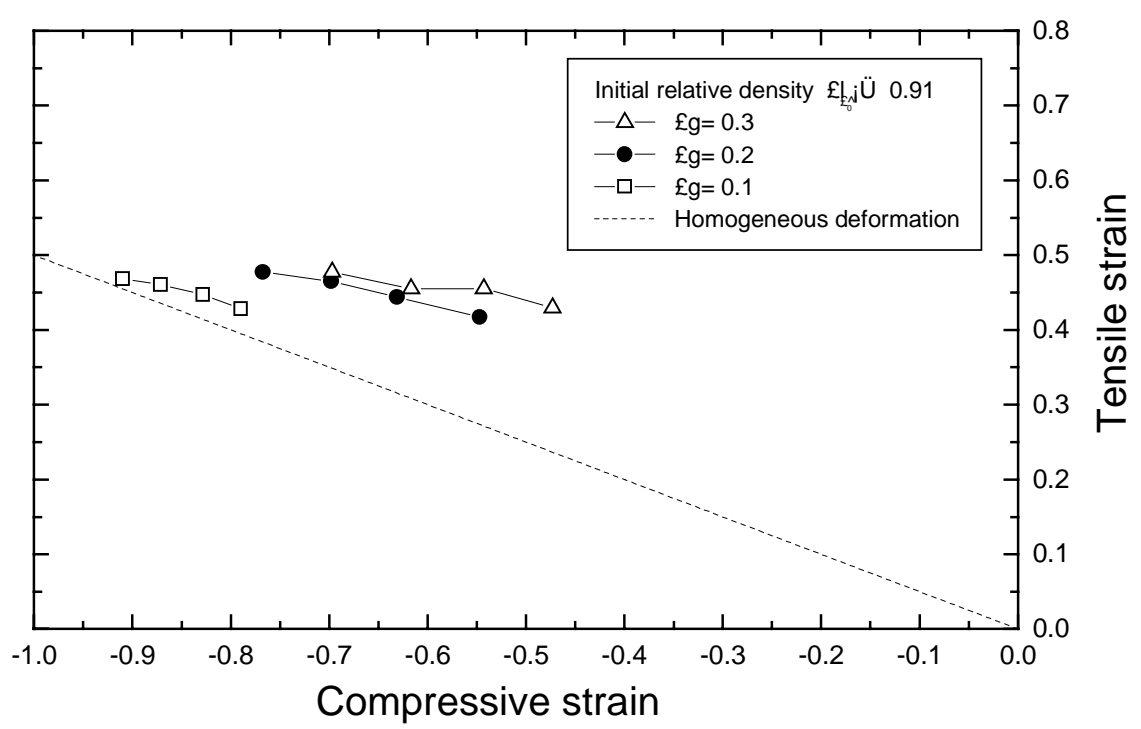

Fig. 15. The fracture strain loci of the billets with the initial relative density of about 0.91 under different coefficients of friction in the upsetting analysis.

\section{Conclusions}

$\mathrm{P} / \mathrm{F}$ technique enhances the dimension precision and the strength of products. Upsetting simulations help better understanding of the workability of sintered preforms. The investigation of the forming limits of porous compacts under various operational conditions is presented. Based on the results of the study, the following conclusions are drawn:

(1) Fracture upsetting simulations, verified with the experiments, are achieved by using the Gurson-Tvergaard yield function for porous media.

(2) The new forming limit criterion for porous metals is formulated with the fracture strain components.

(3) The aspect ratio of porous billets bears a directly proportional relation to the fracture strain during the upsetting.
(4) The increase of voids in material deteriorates the strength and the forging limits.

(5) Higher friction makes it easier to initiate cracks in the workpiece and hence inhibits the workability.

(6) Through the computer simulation of the forging limits of porous materials, we can then predict a fracture even in complicated forging applications. Such capability would be helpful in optimizing the geometry of sintered preforms, the design of the forging die, and the quality of products.

\section{Acknowledgements}

The authors acknowledge the generous support of experimental facilities from Prof. Kuen-Shyang Hwang of the 
Department of Materials Science and Engineering, National Taiwan University. This research was sponsored by the National Science Council of the Republic of China under grant no. NSC 89-2212-E-002-111.

\section{References}

[1] S.P. Keeler, W.A. Backofen, Plastic instability and fracture in sheets stretched over rigid punches, Trans. ASM 56 (1963) 25-48.

[2] S. Kobayashi, Deformation characteristic and ductile fracture of 1040 steel in simple upsetting of solid cylinders and rings, J. Eng. Ind Trans. ASME 92 (1970) 391-403.

[3] S. Kobayashi, Workability of aluminium alloy 7075-T6 in upsetting and rolling, J. Eng. Ind. Trans. ASME 98 (1976) 800-806.

[4] P.W. Lee, H.A. Kuhn, Fracture in cold upset forging-a criterion and model, Metall. Trans. 4 (1973) 969-974.

[5] P.W. Lee, H.A. Kuhn, P/M forging, in: Powder Metallurgy, Metals Handbook, vol. 7, 9th ed., ASM, 1984, pp. 410-418.

[6] G.L. Roy, J.D. Embury, G. Edward, M.F. Ashby, A model of ductile fracture based on the nucleation and growth of voids, Acta Metall. 29 (1981) 1509-1522.

[7] O. Ettouney, D.E. Hardt, A method for in-process failure prediction in cold upset forging, J. Eng. Ind. Trans. ASME 105 (1983) 161167.

[8] Z. Darvas, The forming limit and the fracture mode in cold upsetting, Mater. Sci. Eng. A 70 (1985) 101-110.

[9] F.A. McClintock, A criterion for ductile fracture by the growth of holes, J. Appl. Mech. Trans. ASME 35 (1968) 363-371.

[10] R. Sowerby, N. Chandrasekaran, The prediction of damage accumulation when upsetting AISI 1045 steel specimens, based on McClintock's model, Mater. Sci. Eng. 79 (1986) 27-35.

[11] J.R. Rice, D.M. Tracey, On the ductile enlargement of voids in triaxial stress fields, J. Mech. Phys. Solids 17 (1969) 201-217.

[12] V. Vujovic, A.H. Shabaik, A new workability criterion for ductile metals, J. Eng. Mater. Technol. Trans. ASME 108 (1986) 245-249.

[13] C.L. Downey, H.A. Kuhn, Application of a forming limit concept to the design of powder preforms for forging, J. Eng. Mater. Technol. Trans. ASME 97 (1975) 121-125.
[14] T. Tabata, S. Masaki, A fracture criterion for porous materials and its application to the shape of sintered preforms in forging, J. Eng. Mater. Technol. Trans. ASME 99 (1977) 16-22.

[15] M. Abdel-Rahman, M.N. El-Sheikh, Workability in forging of powder metallurgy compacts, J. Mater. Process. Technol. 54 (1995) 97-102.

[16] J.H. Lee, Y. Zhang, A finite-element work-hardening plasticity model of the uniaxial compression and subsequent failure of porous cylinders including effects of void nucleation and growth. Part II. Localization and fracture criteria, J. Eng. Mater. Technol. Trans. ASME 118 (1996) 169-178.

[17] P. Hartley, C.E.N. Sturgess, G.W. Rowe, Influence of friction on the prediction of forces, Int. J. Mech. Sci. 22 (1980) 743-753.

[18] A.K. Jha, S. Kumar, Deformation characteristics and fracture mechanisms during the cold forging of metal powder preforms, Int. J. Mach. Tool Des. Res. 26 (1986) 369-384.

[19] X.Q. Zhang, Y.H. Peng, M.Q. Li, S.C. Wu, X.Y. Ruan, Study of workability limits of porous materials under different upsetting conditions by compressible rigid-plastic finite element method, J. Mater. Eng. Perfect. 9 (2000) 164-169.

[20] A.L. Gurson, Continuum theory of ductile rupture by void nucleation and growth. Part I. Yield criteria and flow rules for porous ductile media, J. Eng. Mater. Technol. Trans. ASME 99 (1977) 2-15.

[21] V. Tvergaard, Influence of voids on shear band instabilities under plane strain conditions, Int. J. Fract. 17 (1981) 389-407.

[22] S.H. Goods, L.M. Brown, The nucleation of cavities by plastic deformation, Acta Metall. 27 (1979) 1-15.

[23] C.C. Chu, A. Needleman, Void nucleation effects in biaxially stretched sheets, J. Eng. Mater. Technol. Trans. ASME 102 (1980) 249256.

[24] C.L. Hom, R.M. McMeeking, Void growth in elastic-plastic materials, J. Appl. Mech. Trans. ASME 56 (1989) 309-317.

[25] J.H. Lee, Y. Zhang, A finite-element work-hardening plasticity model of the uniaxial compression and subsequent failure of porous cylinders including effects of void nucleation and growth. Part I. Plastic flow and damage, J. Eng. Mater. Technol. Trans. ASME 116 (1994) 69-79.

[26] C.-C. Huang, J.-H. Cheng, Forging simulation of sintered powder compacts under various frictional conditions, Int. J. Mech. Sci., in press.

[27] ABAQUS, Standard User's Manual, Version 5.8, Hibbit, Karlsson \& Sorensen Inc., 2000. 